\title{
AVALIAÇÃO DE UM MÉTODO DE CONSTRASTE POR OXIDAÇÃO PARA A REVELAÇÃO DO GRÃO AUSTENÍTICO PRÉVIO NOS AÇOS ABNT4340 E ABNT1030*
}

\section{Resumo}

Paulo Sérgio Moreira ${ }^{1}$ Rogério Antão Cardoso ${ }^{2}$ Geraldo Lúcio de Faria ${ }^{3}$

O tamanho de grão austenítico prévio é determinante na área de tratamentos térmicos dos aços, pois este parâmetro influencia sua microestrutura e propriedades. Para que o tamanho de grão possa ser medido, é necessário que antes se aplique métodos de contraste para sua revelação. A literatura relata, entre métodos desenvolvidos, dificuldades em se conseguir bons resultados em função deles serem susceptíveis a variações de composição química e histórico de processamento dos aços. Neste contexto, esse trabalho propôs métodos para a revelação dos contornos de grãos austeníticos prévios dos aços ABNT4340 e ABNT1030. Foram utilizadas duas técnicas: ataque químico e ataque térmico. Para a técnica de ataque químico, utilizou-se um reativo a base de ácido pícrico. Já na técnica de ataque térmico, as amostras foram austenitizadas de forma a promover uma oxidação controlada. Os resultados obtidos mostram o sucesso das técnicas, com destaque para o ataque térmico que se mostrou mais efetivo para o objetivo proposto. Foi possível mostrar que no ataque químico, o ajuste da concentração de $\mathrm{HCl}$ em função da composição química do aço é o ponto de maior importância, ao passo que no ataque térmico, a segregação química e a temperabilidade dos aços são relevantes para o sucesso da técnica.

Palavras-chave: Contorno de grão austenítico prévio; Ataque térmico; Constituintes difusionais.

\section{EVALUATION OF AN OXIDATION METHOD FOR PRIOR AUSTENITE GRAIN BOUNDARY REVEALATION IN ABNT4340 AND ABNT1030 STEELS}

\section{Abstract}

The prior austenite grain boundary is very important in steel heat treatment area, because this parameter has a great influence on steel microstructure and properties. Aiming to measure the austenitic grain size, before it is necessary to reveal it applying contrast methods. The technical literature reports the troubles to get good results due to the known methods are susceptible to steel chemical compositions and processing routes. In this context, this paper proposed methods to reveal the prior austenite grain boundary in ABNT 4340 and ABNT 1030 steels. Two techniques were used: chemical and thermal etching. For chemical etching, a reactant based on picric acid was applied. In thermal etching, the samples were austenitized aiming to promote a controlled oxidation. The obtained results show the success of the methods, with highlights for thermal etching which was the most efficient. It was possible to show that in the chemical etching, the $\mathrm{HCl}$ concentration, as a function of steel chemical composition, was the most important adjust parameter. In thermal etching, the chemical segregation and the steel hardenability were relevant for the method succes.

Keywords: Prior austenite grain boundary; Thermal etching; Diffusional constituents.

1 Engenheiro Metalúrgico,MSc., Pesquisador, Departamento de Engenharia Metalúrgica e de Materiais, Universidade Federal de Ouro Preto, Ouro Preto, Minas Gerais e Brasil.

2 Graduando em Engenharia Metalúrgica, Estudante, Departamento de Engenharia Metalúrgica e de materiais, Universidade Federal de Ouro Preto, Ouro Preto, Minas Gerais e Brasil.

3 Físico, Dr., Professor, Departamento de Engenharia Metalúrgica e de Materiais, Universidade Federal de Ouro Preto, Ouro Preto, Minas Gerais e Brasil. 


\section{INTRODUÇÃO}

O conhecimento do tamanho de grão austenítico prévio em aços é de suma importância pois, a partir desse estudo, pode-se prever parâmetros metalúrgicos que influenciarão diretamente em suas propriedades. O tamanho médio dos grãos austeníticos prévios têm forte influência sobre a microestrutura e propriedades mecânicas finais da liga, visto que quanto menor o seu valor, em geral, maior será o número de sítios para a nucleação heterogênea, favorecendo assim à cinética de nucleação e crescimento de constituintes difusionais, refinando a sua microestrutura. A microestrutura obtida após o resfriamento contínuo confere aos aços propriedades que influenciarão diretamente em seu desempenho [1-4].

Os métodos de contraste conhecidos e utilizados para se revelar o tamanho de grão austenítico prévio são de difícil aplicação e sua eficiência nem sempre atingem os objetivos propostos. Alguns fatores como a composição química e tratamentos térmicos influenciam a resposta à aplicação destas técnicas de revelação. Neste contexto, são requeridas metodologias mais eficazes que evidenciem com melhor nitidez os contornos de grão austeníticos prévio [4-6].

Existem métodos indiretos para revelar o contorno de grão austenítico prévio, como, por exemplo, a técnica de ataque químico e a técnica de ataque térmico. A técnica de contraste por ataque químico é largamente utilizada, de forma que que reativos à base de ácido pícrico apresentam melhor eficiência para aços temperados [6,7].

O reativo à base de ácido pícrico é indicado também para aços com médio e alto teor de carbono e a efetividade do ataque ocorre principalmente em função da segregação química de fósforo nos contornos de grão austeníticos durante a austenitização do aço. Entretanto, encontra-se certa dificuldade para aplicação deste ataque em aços com baixo teor em carbono, principalmente quando a microestrutura é majoritariamente martensítica [7].

No ataque químico à base de ácido pícrico, verifica-se que a quantidade de ácido clorídrico e do detergente neutro no reativo têm influência sobre o sucesso da técnica. $O$ detergente neutro é um agente tensoativo que acentua a molhabilidade da superfície da amostra, controlando o ataque químico e levando a um resultado mais uniforme. O ácido clorídrico potencializa a ação do ácido pícrico, porém, por possuir elevado potencial corrosivo, sua adição deve ser controlada [8].

A fração de carbono presente no aço é um parâmetro de relevância para a escolha da quantidade de ácido clorídrico a ser adicionado ao reativo. Quanto maior o teor em carbono, menor quantidade de ácido clorídrico deve ser adicionada, pois o aparecimento de grande fração de pites de corrosão podem deteriorar a superfície da amostra $[8,9]$.

O método de contraste por ataque térmico consiste na revelação do contorno de grão austenítico prévio em amostra de aço com a superfície pré-polida. Segundo Rabkin e Klimger (2001), a formação de ranhuras nas interseções dos contornos de grãos austeníticos com a superfície polida, enquanto o aço é exposto a uma elevada temperatura em atmosfera inerte, marcam o contorno de grão austenítico e estas marcas são visíveis ao microscópio óptico à temperatura ambiente [4,11]. A formação de ranhuras nos contornos de grão ocorre devido à transferência de material ao longo dos contornos pelos mecanismos de transporte de matéria (evaporação-condensação, difusão em volume e difusão superficial) [6]. Os resultados do ataque térmico resultam da tríplice junção entre o contorno de grão e a superfície livre da amostra $[4,11]$. 
O método por ataque térmico é considerado o mais rápido e o mais prático e, após o tratamento térmico, não é necessário o polimento da superfície da amostra. Ao contrário de outros métodos, no método de ataque térmico, não necessariamente as amostras deverão estar temperadas [4,6].

Esse trabalho tem como caráter inovador o desenvolvimento de novas técnicas de contraste para revelar com melhor eficiência o contorno de grão austenítico prévio, dando enfoque ao ataque térmico com oxidação controlada. Foram avaliadas duas técnicas de contraste para revelar o contorno de grão austenítico prévio em aço ABNT 4340 e ABNT 1030 e, em seguida, os resultados dos dois tipos de aço (ABNT 4340 e ABNT 1030) foram comparados.

\section{MATERIAIS E MÉTODOS}

\subsection{Materiais}

As Tabelas 1 e 2 apresentam, respectivamente, a composição química das amostras dos aços ABNT 4340 e ABNT 1030 recebidos no Laboratório de Tratamentos Térmicos e Microscopia Óptica (LTM) do DEMET-EM-UFOP para desenvolvimento deste estudo. O aço ABNT4340 é um aço baixa liga com teor de C próximo a 0,4\% e concentrações significativas de $\mathrm{Ni}(1,67 \%)$, $\mathrm{Cr}(0,73 \%)$, Si $(0,34 \%)$ e Mo $(0,29 \%)$. O aço ABNT 1030 é um aço carbono comum, com manganês de 0,6\%. Estes aços foram selecionados para a realização deste estudo por possuírem características químicas distintas, permitindo assim, a avaliação da eficiência das técnicas de ataque testadas para aços diferentes.

Tabela 1: Composição química do aço ABNT 4340 (\% em massa).

\begin{tabular}{|c|c|c|c|c|c|c|c|}
\hline $\mathrm{C}$ & $\mathrm{Mn}$ & $\mathrm{P}$ & $\mathrm{S}$ & $\mathrm{Si}$ & $\mathrm{Ni}$ & $\mathrm{Cr}$ & $\mathrm{Mo}$ \\
\hline 0,40 & 0,70 & 0,02 & 0,02 & 0,34 & 1,67 & 0,73 & 0,29 \\
\hline $\mathrm{Al}$ & $\mathrm{V}$ & $\mathrm{Nb}$ & $\mathrm{B}$ & $\mathrm{Ti}$ & - & - & - \\
\hline 0,029 & 0,006 & 0,004 & 0,001 & 0,002 & - & - & - \\
\hline
\end{tabular}

Tabela 2: Composição química do aço ABNT 1030 (\% em massa).

\begin{tabular}{|c|c|c|c|c|c|c|c|c|}
\hline $\mathrm{C}$ & $\mathrm{Mn}$ & $\mathrm{P}$ & $\mathrm{S}$ & $\mathrm{Si}$ & $\mathrm{Ni}$ & $\mathrm{Cr}$ & $\mathrm{Mo}$ & $\mathrm{Al}$ \\
\hline 0,27 & 0,60 & 0,02 & 0,02 & 0,14 & 0,07 & 0,07 & 0,009 & - \\
\hline
\end{tabular}

\subsection{Procedimentos Experimentais}

Neste estudo, foram avaliadas duas técnicas de contraste para a revelação do contorno de grão austenítico prévio: o ataque químico por imersão e o ataque térmico (nova proposta). Para tanto, foram definidos procedimentos experimentais específicos, apresentados por meio de fluxogramas nas Figuras 1, 2 e 3.

$\mathrm{O}$ ataque químico por imersão teve como base o trabalho de Moreira et al.(2015) no qual foram testadas composições distintas de um reativo a base de ácido pícrico e diferentes tempos de ataque. Dessa forma, foram propostas novas condições de ataque químico por imersão, cujos resultados foram comparados ao ataque térmico.

Na Figura 1 está apresentado o fluxograma do ataque químico por imersão ao qual as amostras dos aços ABNT4340 e ABNT1030 foram submetidas. Neste procedimento, as amostras dos dois tipos de aços foram austenitizadas e resfriadas em água a temperatura ambiente, uma vez que a condição de resfriamento rápido (tratamento térmico de têmpera) é essencial para a efetividade do método [12]. Na 
sequência, as amostras dos dois tipos de aços foram submetidas à preparação metalográfica (lixamento e polimento) e foram atacadas quimicamente, por imersão, com o reativo à base de ácido pícrico. Ainda nesta avaliação, houve variação da quantidade de $\mathrm{HCl}$ adicionado ao reativo, bem como do tempo de ataque.

$\mathrm{Na}$ Figura 2 pode-se observar o fluxograma do ataque térmico proposto. $\mathrm{O}$ ataque térmico foi realizado em atmosfera controlada com argônio de forma a promover uma oxidação superficial controlada do material no campo de estabilidade austenítico. Para que o procedimento seja efetivo, é necessário que a superfície da amostra já esteja lixada e polida antes de sua austenitização. A diferença entre as condições do ataque térmico apresentadas pelo fluxograma da Figura 2 está no meio de resfriamento ao qual as amostras foram submetidas (ao ar e em água). Após a avaliação das técnicas de contraste, as amostras dos dois aços foram novamente preparadas para a caracterização da microestrutura original, ou seja, aquela gerada após os tratamentos térmicos.

Para todas as técnicas de ataque avaliadas, as amostras foram posteriormente submetidas a análises microestruturais ao microscópio óptico (MO) e microscopia eletrônica de varredura (MEV). Foi utilizado um microscópio óptico LEICA do Laboratório de Tratamentos Térmicos e Microscopia Óptica (LTM) do DEMET-EMUFOP e o microscópio eletrônico de varredura TESCAN do Nanolab da REDEMATUFOP.

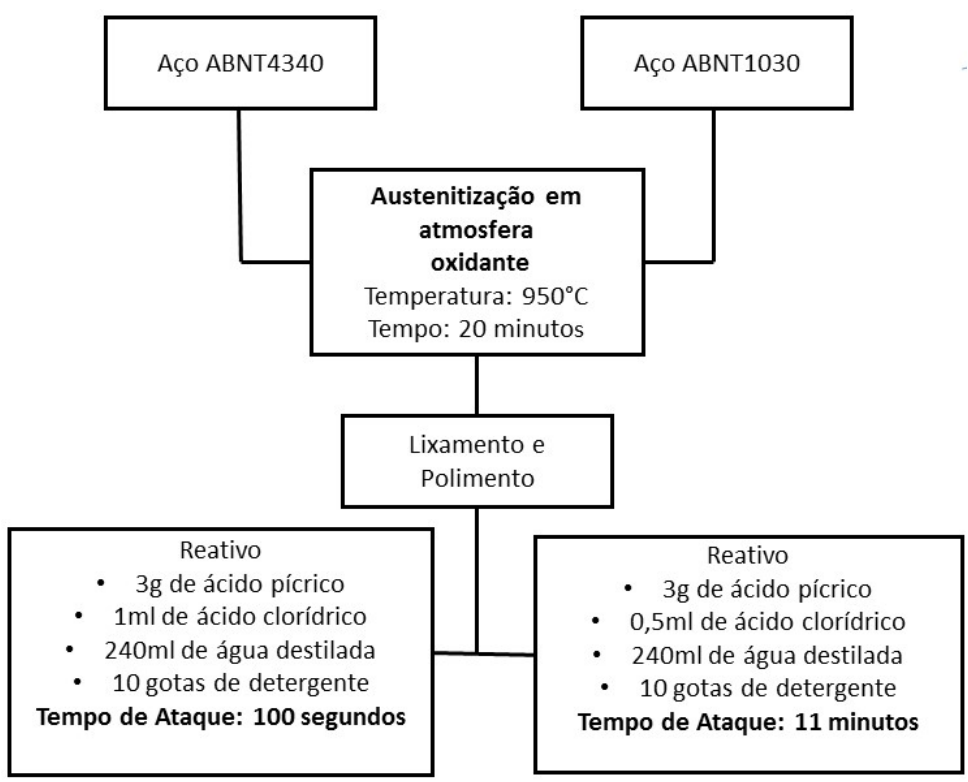

Figura 1: Fluxograma do ataque químico com o Reativo a base de ácido pícrico para amostras dos aços ABNT4340 e ABNT1030. 


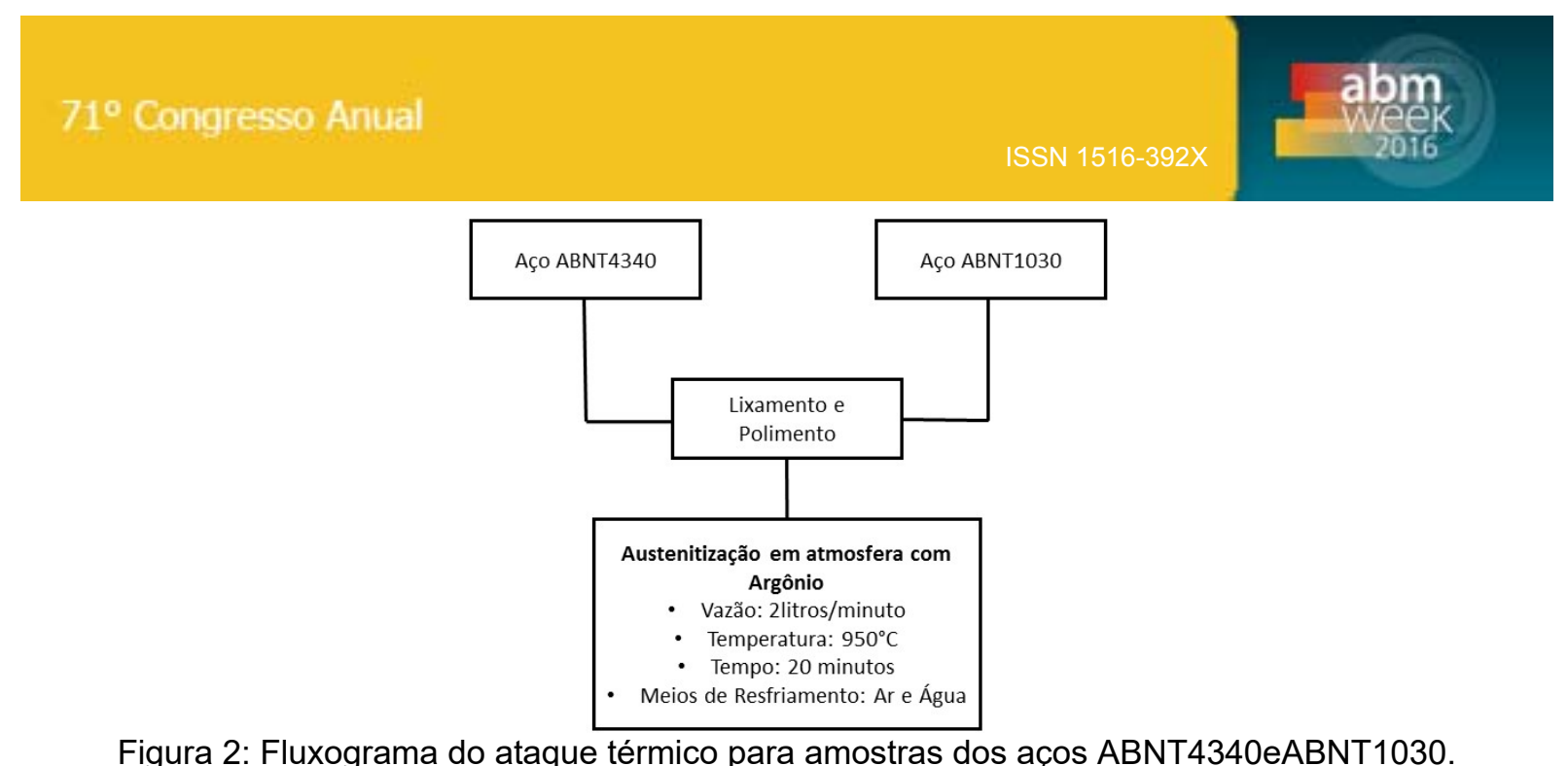

Figura 2: Fluxograma do ataque térmico para amostras dos aços ABNT4340eABNT1030.

\section{RESULTADOS E DISCUSSÃO}

\subsection{ATAQUE QUÍMICO}

Os resultados obtidos pela aplicação da técnica de ataque químico, a base de ácido pícrico, para a revelação do contorno de grão austenítico prévio dos aços ABNT4340 e ABNT1030 estão apresentados na Figura 3. Nos dois tipos de aços é possível perceber a delineação dos contornos de grãos austeníticos prévios. O sucesso deste método se deu em função da adequação da quantidade de $\mathrm{HCl}$ adicionado ao reativo, em função da composição química dos aços estudados [8,9].

O aço ABNT4340 apresenta significativo teor de elementos de liga, possuindo assim maior carbono equivalente $(0,83)$ do que o ABNT $1030(0,39)$ [13]. Como descrito por Moreira et al. (2015), a adição de $\mathrm{HCl}$ neste reativo, tem como principal função potencializar o efeito corrosivo na superfície atacada. Em geral, aços com maior carbono equivalente são mais susceptíveis à ação desta substância. Neste contexto, o reativo utilizado no ataque do aço ABNT 4340 foi confeccionado com adição de apenas $0,5 \mathrm{ml}$ de $\mathrm{HCl}$, enquanto aquele utilizado no ataque do ABNT $1030,1 \mathrm{ml}$ de $\mathrm{HCl}$.

Em geral, reativos a base de ácido pícrico, quando aplicados em aços ligados, ou microligados, tendem a reagir com elementos químicos segregados no contorno de grão austenítico durante a austenitização e que, no resfriamento rápido, não tiveram tempo suficiente para se difundirempara o volume do grão. Estas regiões de alta energia são mais susceptíveis à ação do reativo, e então, delimitam onde antes estavam os contornos de grão da austenita [6].

O aço ABNT 4340, por possuir maior concentração de elementos de liga e, alguns com baixa solubilidade na austenita, como por exemplo $\mathrm{Cr}$, Mo, Si e P, pode apresentar significativa segregação destes elementos nos contornos de grão da austenita [5, 14, 15]. Neste contexto, a eficácia do reativo à base de ácido pícrico é esperada, como pode-se observar nas Figuras 3-A e 3-B.

No aço ABNT 1030, que possui menor carbono equivalente e baixa temperabilidade, a segregação nos contornos de grão austeníticos não seria o principal mecanismo de geração de contraste, mas sim a ação do reativo sobre constituintes difusionais nucleados no contorno de grão austenítico durante o resfriamento. Como o aço ABNT 1030 é de baixa temperabilidade, mesmo sendo ele temperado em água, há significativa formação de bainita e possivelmente de ferrita alotriomorfa e de Widmanstätten nos contornos de grão auteníticos [16]. Estas áreas, quando atacadas 
pelo reativo em questão, delimitam o contorno de grão austenítico prévio. Nas Figuras 3-C e 3-D é possível perceber, por meio de microscopia óptica, uma delineação mais espessa, sendo um indicativo da presença de constituintes difusionais formados no resfriamento e que geraram contraste após ataque químico. A mesma verificação não é observada para o aço ligado, onde as linhas dos contornos são bem mais finas.

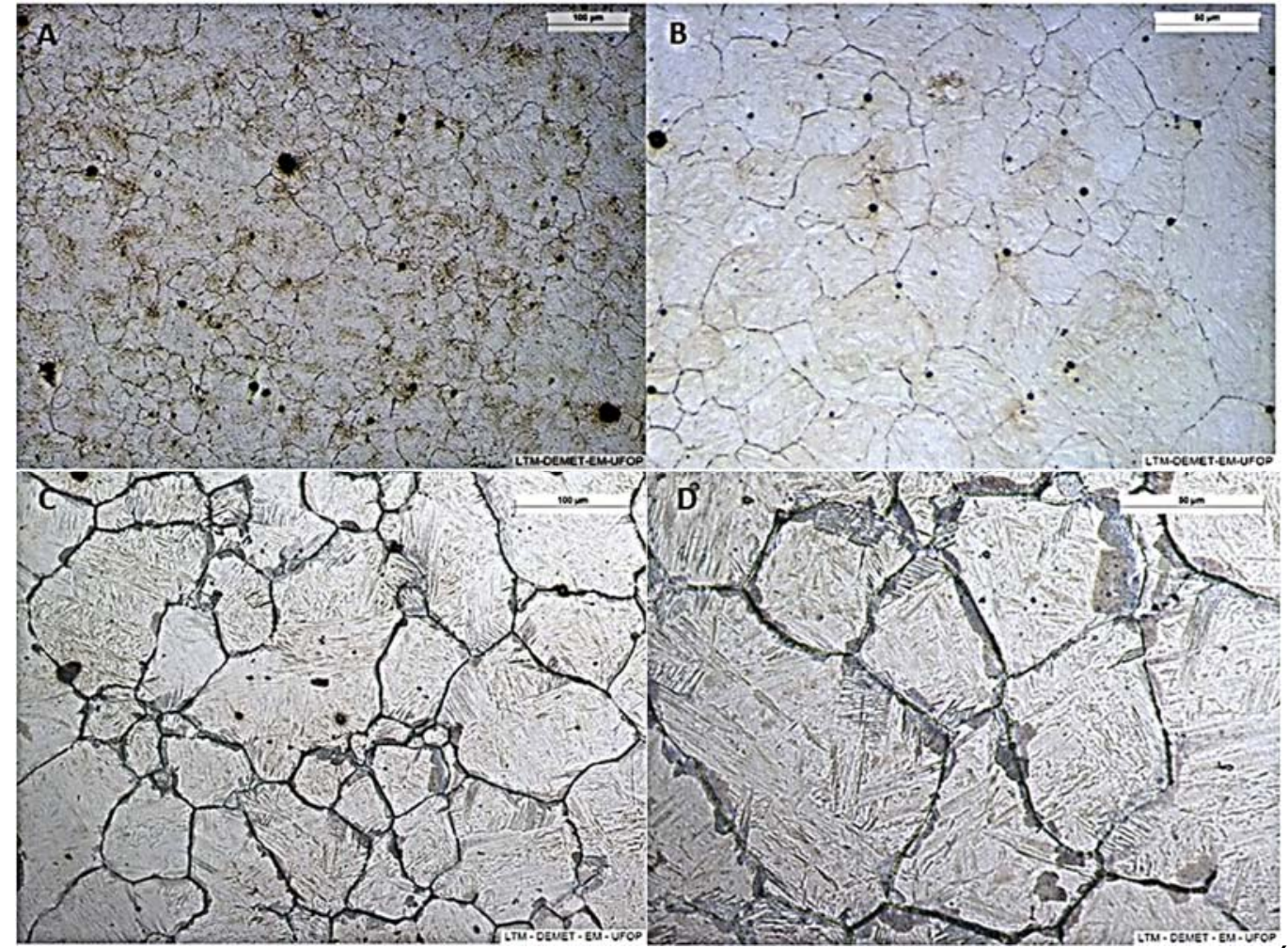

Figura 3: Contornos de grão austeníticos prévios revelados por ataque químico. Microscopia Óptica. (A) ABNT4340 -200x, (B) ABNT4340 - 500x, (C) ABNT1030 - 200x, (D) ABNT1030 - 500x.

\section{2 - ATAQUE TÉRMICO}

A Figura 4 apresenta os resultados obtidos pela aplicação da técnica de ataque térmico seguido do resfriamento ao ar. Verifica-se que essa técnica foi mais eficaz para o aço ABNT4340, pois, este apresentou oxidação preferencial no contorno de grão austenítico. Esta oxidação preferencial se dá pelo fato da difusão do oxigênio no aço ser facilitada em regiões de alta energia. Sabe-se da teoria clássica de difusão que a difusão em contorno de grão é maior do que em volume, uma vez fixados a temperatura e o tempo para que o fenômeno ocorra. Este efeito pode ter sido potencializado pela segregação de elementos de liga no contorno de grão austenítico deste aço $[4,6,11]$.

Para o aço ABNT1030 esse mecanismo de contraste não foi efetivo. Como este aço possui baixa temperabilidade e baixa temperatura de início de transformação martensítica, provavelmente, durante o resfriamento lento do aço em atmosfera controlada, houve significativa formação de ferrita e de colônias de perlita, cujos contornos de grão também foram oxidados, não sendo possível assim distinguir os contornos austeníticos prévios dos contornos destes constituintes difusionais. Estas características podem ser observadas nas Figuras 4-C e 4-D.

Buscando comprovar que os contornos revelados por meio da aplicação do ataque térmico do aço ABNT4340 são efetivamente os contornos austeníticos prévios, a 
amostra submetida a este procedimento foi metalograficamente preparada e submetida ao tradicional ataque Villela $(2 \mathrm{~g}$ de Ácido Pícrico, $5 \mathrm{ml}$ de Ácido Clorídrico e $100 \mathrm{ml}$ de Álcool Etílico). Pode-se perceber que a microestrutura deste aço, após submissão ao ataque térmico, é constituída por martensita e bainita (Figura 5-A). $O$ aço ABNT 1030 também foi submetido à mesma metodologia, porém atacado com o reativo Nital $2 \%$ ( $2 \mathrm{ml}$ de Ácido Nítrico e $98 \mathrm{ml}$ de Álcool Etílico). Pode-se observar que sua microestrutura é constituída por ferrita e perlita (Figura 5-B). Estas observações confirmam as hipóteses anteriormente apresentadas.

Por meio da análise via microscopia eletrônica de varredura (MEV) e utilizando-se também o recurso do EDS, foi possível caracterizar de forma mais detalhada a microestrutura da amostra do aço ABNT4340 submetida ao ataque térmico seguido do resfriamento ao ar. Na Figura 6, pode-se observar a efetividade da técnica, pois os contornos de grãos austeníticos prévios estão claramente revelados.
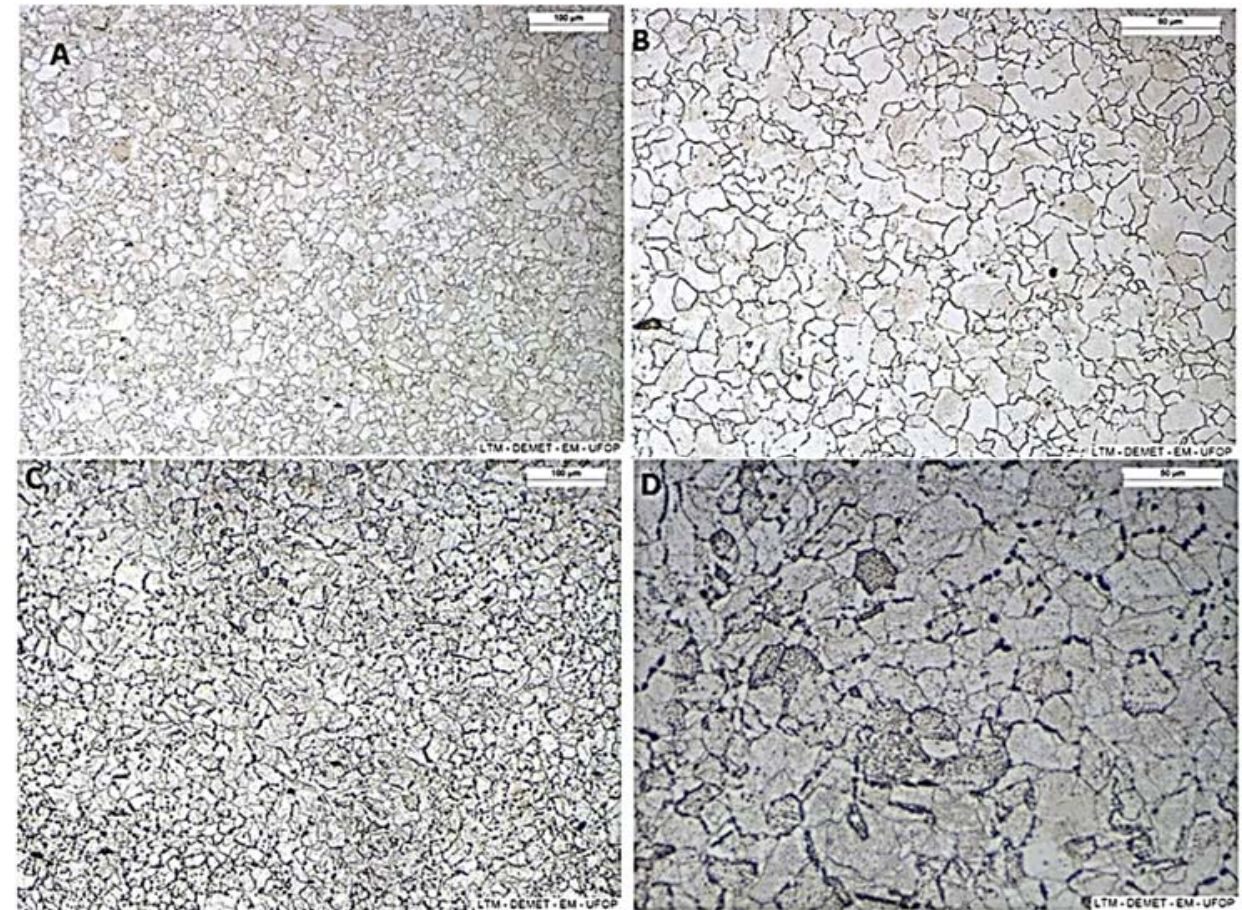

Figura 4: Contornos de grão austeníticos prévios revelados por ataque térmico seguido do resfriamento ao ar. Microscopia Óptica. (A) ABNT4340 -200x, (B) ABNT4340 - 500x, (C) ABNT1030 $-200 x$, (D) ABNT1030 - 500x.
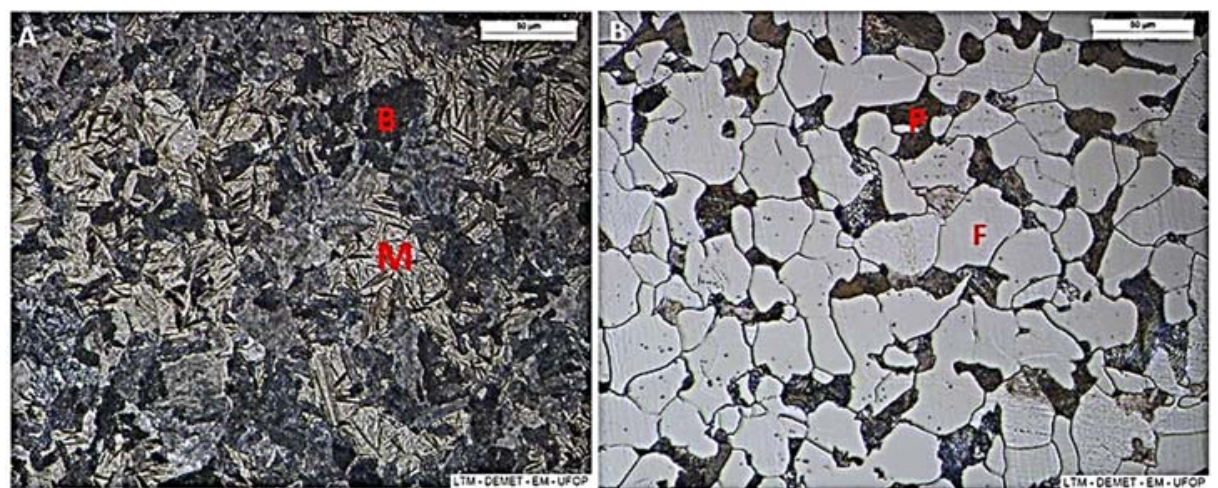

Figura 5 - Microestruturas formadas após a técnica de ataque térmico, seguido do resfriamento ao ar. (A) Aço ABNT4340, martensita (M) e bainita (B) - 500x. (B) Aço ABNT1030, perlita (P) e ferrita (F) $500 x$. 

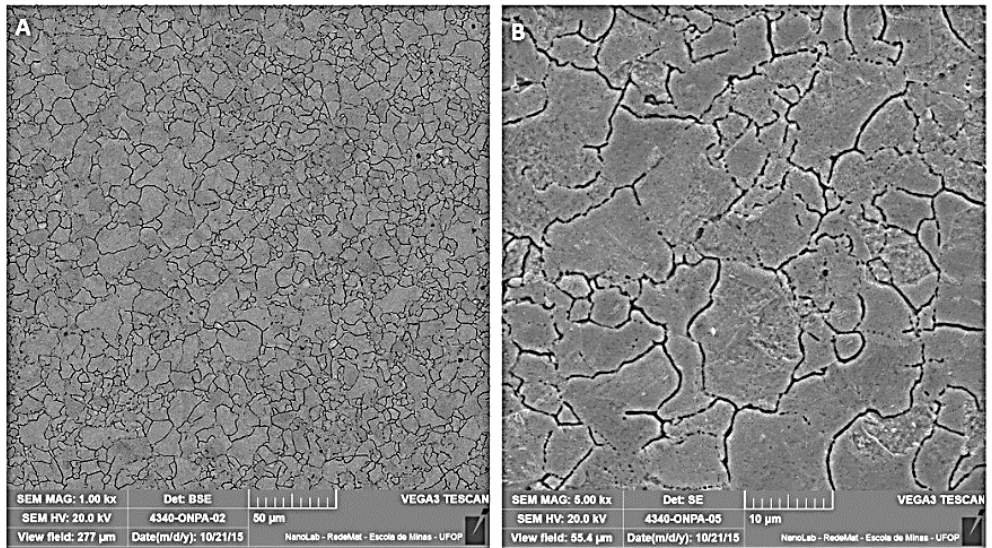

Figura 6: Contornos de grão austeníticos prévios revelados por ataque térmico seguido do resfriamento ao ar. MEV.(A) ABNT4340 -1000x, (B) ABNT4340 - 5000x

Pelas imagens da Figura 6, percebe-se nitidamente a oxidação preferencial com o aparecimento de ranhuras (regiões escuras). Segundo Andres et.al. (2003) e Rabkin et.al. (1991) estas ranhuras marcam o contorno de grão austenítico. Verificou-se também por meio do mapeamento por EDS (Figura 7) a segregação preferencial de silício nestas regiões escuras, confirmando a existência dos contornos de grãos austeníticos prévios.

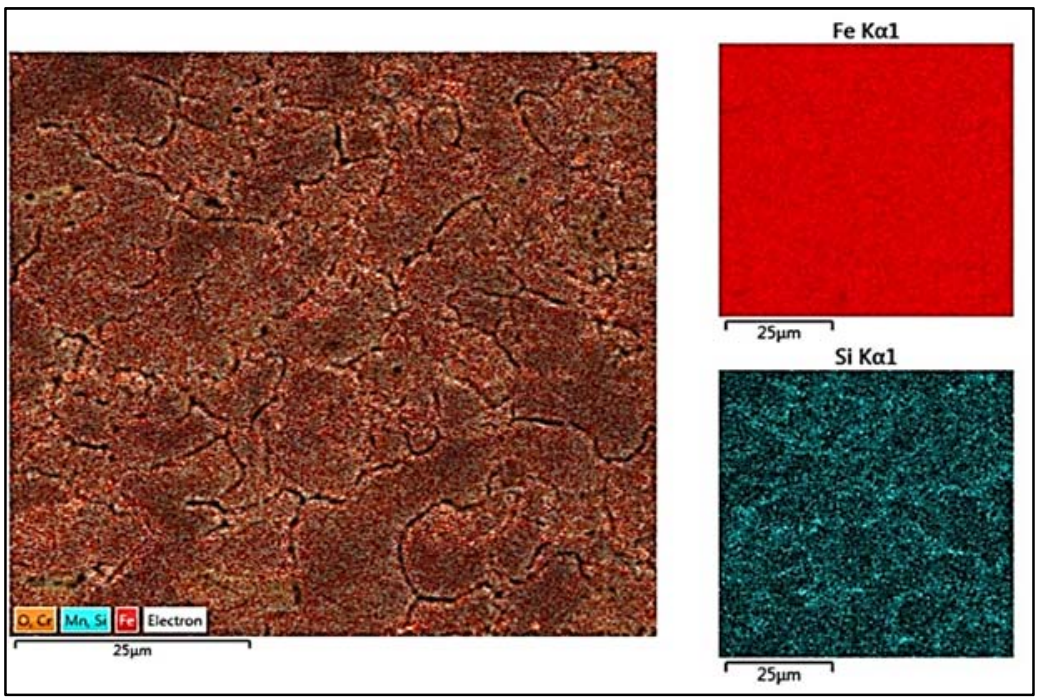

Figura 7: Mapeamento MEV-EDS da superfície do aço ABNT4340 submetido ao ataque térmico e resfriado ao ar.

As Figuras 8 e 9 apresentam os resultados obtidos para a aplicação da técnica de ataque térmico seguido do resfriamento em água, para a revelação do contorno de grão austenítico prévio dos aços ABNT4340 e ABNT1030, respectivamente. As análises foram realizadas por meio da aplicação de microscopia eletrônica de varredura. 

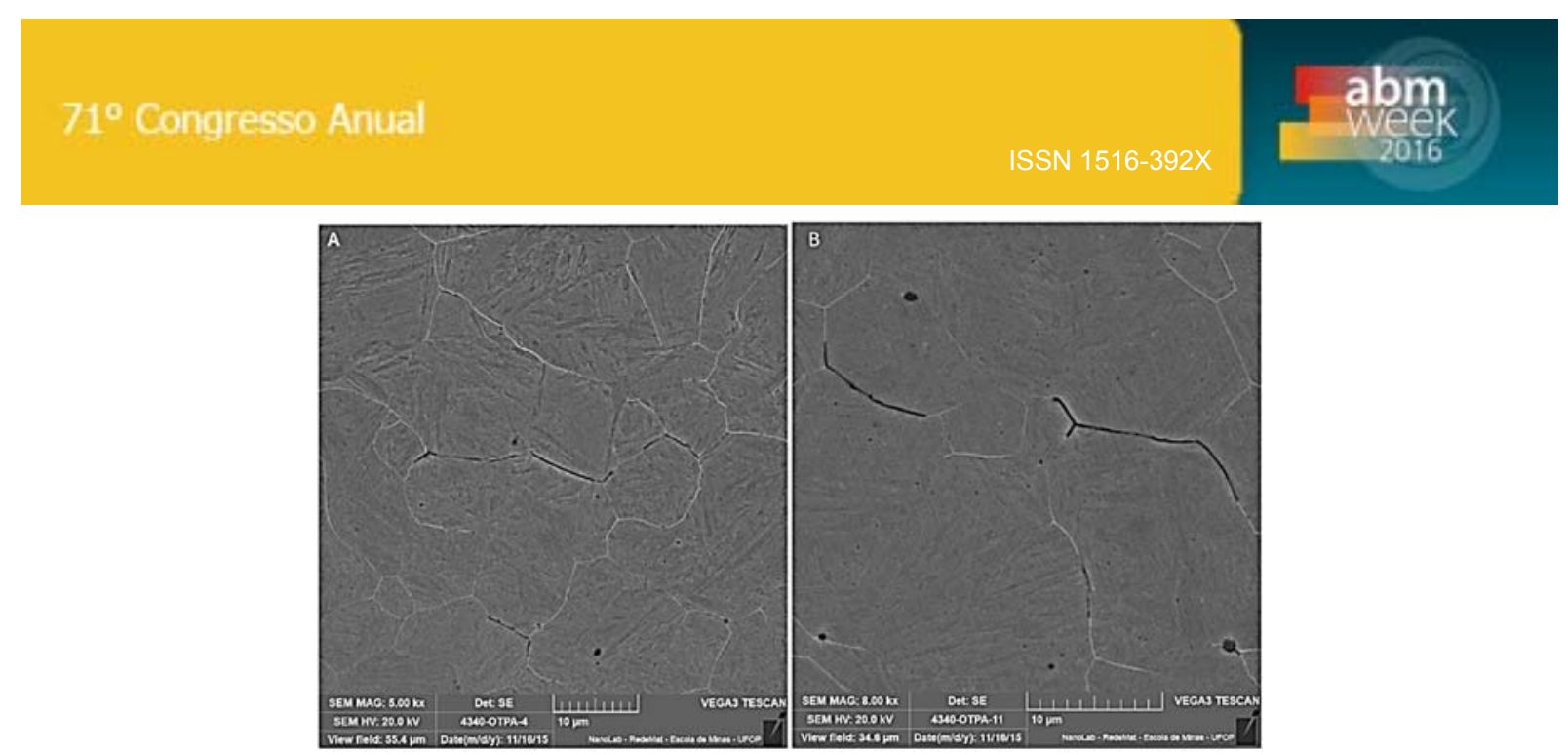

Figura 8: Contornos de grão austeníticos prévios revelados por ataque térmico seguido do resfriamento em água. MEV.(A) ABNT4340 - 5000x, (B) ABNT4340 - 8000x.

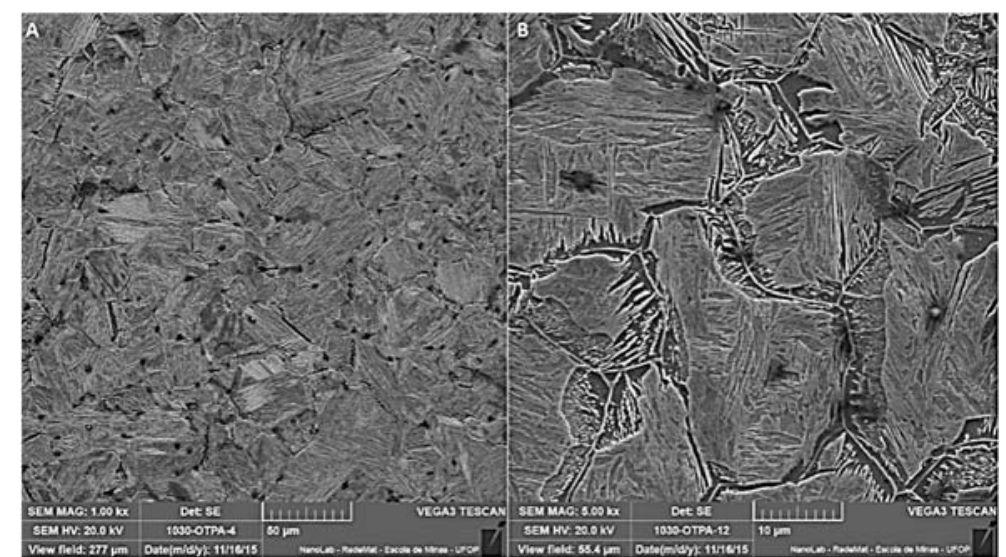

Figura 9: Contornos de grão austeníticos prévios revelados por ataque térmico seguido do resfriamento em água. MEV.(A) ABNT1030 - 1000x, (B) ABNT1030 - 5000x.

Para os dois tipos de aços os resultados foram satisfatórios. Na Figura 8 verifica-se a formação de trincas intergranulares características de têmpera neste tipo de aço. $\mathrm{O}$ aço ABNT4340 tem alta temperabilidade e o resfriamento rápido propicia o aparecimento de fissuras (trincas de têmpera) preferencialmente localizadas nos contornos de grão austeníticos, sendo uma característica marcante que define bem esses contornos. O contorno de grão é uma região de alta energia, onde ocorre segregação química, promovendo alta tensão residual quando a expansão volumétrica decorrente da transformação martensítica ocorre. Estas regiões se tornam concentradores de tensão e, portanto, locais preferenciais para a nucleação de trincas de têmpera. Além das trincas, observa-se a presença de pontos de oxidação distribuídos preferencialmente nos contornos de grão.

Para o aço ABNT1030 observou-se também a presença de pontos de oxidação localizados majoritariamente nos contornos de grão (Figura 9-A). Essa oxidação pode criar uma barreira térmica que, influencia a taxa local de resfriamento nestas áreas, diminuindo-a. Esta ocorrência, associada à baixa temperabilidade deste aço, promoveu a formação de constituintes difusionais na região dos contornos de grãos austeníticos prévios, ficando a martensita restrita à região mais central do grão austenítico.

A amostra do aço ABNT 1030 termicamente atacada, foi metalograficamente preparada (lixamento e polimento) e atacada com Nital $2 \%$ para confirmarção desta hipótese. Na Figura 9-B observa-se o resultado obtido. Percebe-se a formação de constituintes difusionais, com a morfologia de placas formadas nos contornos de grão da austenita, característico da ferrita de contorno de grão. Verifica-se também 
regiões com concentração de carbonetos (Fe3C que se formam entre as placas de ferrita, caracterizando a bainita). A formação destes constituintes em regiões preferenciais comprova a existência do contorno de grão austenítico prévio que foi revelado por ataque térmico.

\section{CONCLUSÃO}

As duas técnicas de contraste para a revelação do contorno de grão austenítico prévio apresentaram resultados satisfatórios.

Para o ataque químico à base de ácido pícrico, verificou-se que a composição química do aço interfere diretamente na efetividade do ataque pois, quanto maior o carbono equivalente do aço, menor será a quantidade de $\mathrm{HCl}$ a ser adicionada no reativo.

O ataque térmico proposto se mostrou eficiente ao revelar, com maior clareza, os contornos de grãos austeníticos prévios. Entretanto, deve-se destacar que o método que emprega o resfriamento ao ar se mostrou eficaz apenas para o aço de maior temperabilidade, ao passo que o método de resfriamento em água se mostrou efetivo para os dois aços estudados.

Ainda em relação ao ataque térmico, pôde-se concluir que os principais mecanismos de contraste responsáveis pela revelação dos contornos de grãos austenítcos prévios, foram: para o aço ABNT 4340 - oxidação preferencial e aparecimento de ranhuras sobre o contorno de grão austenítico durante a austenitização, onde verificou-se também a segregação química do Si; para o aço ABNT 1030 - oxidação preferencial e formação de ferrita e bainita nos contornos de grãos austeníticos durante o resfriamento rápido em água.

\section{REFERÊNCIAS}

1 Nakamura, M., Furubayashi, E., Effectofgrainsizeon crack propagationof high strengthsteel in gaseoushydrogenatmosphere, Materials Science and Technology, vol.6, p.604-610, July 1990.

2 Martins, Priscila Gabriela Melo. Influência da Temperatura e do Tempo de Austenitização sobre o Tamanho de Grão Austenítico de um Aço ABNT 1045." Monografia de Graduação em Engenharia Metalúrgica. Departamento de Engenharia Metalúrgica e de Materiais, Escola de Minas, Universidade Federal de Ouro Preto, Agosto de 2013.

3 Richard A. Schreiman, BuehlerLtd. ResearchandDevelopmentLaboratory. Estimationof prior-austenitegrainsize in heattreatedmartensiticcarbonandlowalloysteels, Lake luff, IL 60044 Wendy J. Bolton, Gulf Coast Laboratory Services, Houston, TX 77429.

4 Andres, C.G.de; Caballero, F. G.; Capdevila, C.; Martin, D.S. Revealing austenite grain boundaries by thermal etching: advantages and disadvantages. MaterialsCharacterization. 2003; v.49: 121 - 127.

5 Ferdian, C.; Ariati, M. \&Norma, A. Method for detecting austenite grains in low-carbon steel after hot deformation. Metal Science and Heat Treatment. 2013; v.55:5 - 6.

6 Andres, C.G.de; Bartolomé, M. J.; Capdevila, C.; Martin, D.S.; Caballero, F. G.; lópez, $\mathrm{V}$. Metallographic techniques for the determination of the austenite grain size in medium-carbon microalloyed steels. MaterialsCharacterization. 2001; v.46: 389 - 398.

7 ZHANG, L. \& GUO, D.C. A General Etchant for Revealing Prior-Austenite Grain Boundaries in Steels. MaterialsCharacterization. 1993; v.30: 299 - 305.

8 Reiter, J., Bernhard, C., Presslinger, H. Austenitegrainsize in thecontinuouscastingprocess: Metallographicmethodsandevaluation. MaterialsCharacterization. 2008; v.59: 737 - 746. 
9 BREWER, A. W.; ERVEN, K. A.; KRAUSS, G. Etching and image analysis of prior austenite grain boundaries in hardened steels. MaterialsCharacterization. 1991; v.27: $53-56$

10 Ogura, T.,McMahon,C.J., Feng,Jr.H.C., Vitek, V. StructureDependentIntergranularSegregationofPhosphorus in Austenite in a Ni- $\mathrm{Cr}$ Steel. Acta Metallurgica. 1975; v.26:1317-1330.

11 Rabkin, E. and Klinger, L. The fascination of the grain boundary grooves. La Revue de Métallurgie-CIT/Science et Génie des Matériaux. 2001; 1059 - 1064.

12 Moreira, P.S.; Faria, G.L.; Fortes, R.C.; Rodrigues, R.A. Avaliação de Diferentes Técnicas de Contraste para Revelar o Contorno de Grão Austenítico Prévio em Aços.ABM WeeK. 2015. v.70.

13 IIW/IIS DOC. 452-74. Weld Metal Hydrogen Level sand the Definition of Hydrogen Controlled Electrodes. Welding in the World. 1974; 12(3/4), 69-65.

14 KUZMINA, M., PONGE, D., RAABE, D. Grainboundarysegregationengineeringandaustenitereversionturnembrittlementintotough ness: Exampleof a 9wt.\% médium Mn steel. Acta Materialia. 2015; v.86:182-192.

15 NASIM, M., Edwards, B. C., Wilson, E. A. A studyofgrainboundaryembrittlement in an Fe-8,1\% Mn alloy. Materials Science andEngineering: A. 2000; v.281:56-67.

16 Mendes, M. K. O., Faria, G. L., Maciel, P. H. C. Efeito da Composição Química e Temperatura de Austenitização Sobre a TemperabilidadeJominy de Aços Baixo Carbono. ABM WeeK. 2015. v.70 